\title{
For Student's Motivation: The Role of Coping
}

\author{
Zahra Bouchkioua \\ Department of psychology, Faculty of Literature and human sciences, Mohammed V University, \\ Rabat, Morocco \\ zahra.bouchkiouadflsh.um5.ac.ma
}

\section{ABSTRACT}

Motivation is what we think we can do. According to the socio-cognitive approach, self-efficacy is one of the six most essential constituents of reason. This feeling encompasses all of the individual's beliefs about their abilities to implement the behaviors they deem helpful to achieve the desired results. The Sense of Perceived Personal Efficacy influences the choice of activities, performance, the expenditure of effort, persistence in the face of difficulties, positive or negative thoughts, and emotional reactions. These beliefs regulate human behavior according to four processes, primarily the affective process (coping principally). The Sense of Self-Efficacy is based on four factors: lived experience, vicarious experience, verbal persuasion, emotional or physiological states, and sources of information about the Sense of SelfEfficacy. This article summarizes research that revolves around the following questions: is there a link between feelings of Perceived Self-Efficacy and coping strategies; can we act on the student's motivation through his Sense of Perceived Self-Efficacy possibly modifiable by coping strategies?

Keywords: conscious training, the sense of perceived self-efficacy, socio-cognitive, coping

Cite this article as: Bouchkioua, Z. (2021). For Student's Motivation: The Role of Coping. International Journal of Higher Education Pedagogies, 2(1), 19-31. https://doi.org/10.33422/ijhep.v2i1.30

\section{Introduction}

Motivation is what everyone thinks can do (Bandura, 1986). One of its most important constituents is a Sense of Perceived Self-Efficacy. It encompasses all of the individual's beliefs (Deci \& Ryan, 2000) about their abilities to implement the behaviors (Wernersbach et al., 2014) they deem helpful to achieve the desired results (Stajkovic \& Luthans, 1998) and face selfeducation and social challenges (Zimmerman,1995a). The Sense of Perceived Self-Efficacy (Bandura, 1989a) influences the choice of activities, performance (Earley, 1994), expenditure of effort, persistence in the face of difficulties, positive or negative thoughts, and emotional reactions. These beliefs regulate human behavior (Schunk \& Zimmerman, 2008) according to four processes (Bandura, 1993): the cognitive process (anticipatory thoughts), the motivational process (primarily cognition or forward-looking thoughts), the affective process (mainly coping), and the selective process (notably the feeling of being out), and Self-efficacy and choice of activities. This Sense of Self-Efficacy in learning is intimately linked to cognitive and self-regulatory abilities (Zimmerman, 1995b), such as time management and activity selection. This feeling interacts with motivational behaviors as the formation of goals, personal standards, outcome expectations (Hsu et al., 2007), and causal attributions (Tolli \& Schmidt, 2008) through the different stages of behavior: initiation, orientation, intensity, and persistence. The Sense of Self-Efficacy is based on four factors: lived experience, vicarious experience, verbal persuasion, emotional or physiological states, and Sources of Information on SelfEfficacy (Bandura, 1986). This article summarizes research that revolves around the following questions: is there a link between Sense of Perceived Self-Efficacy and coping strategies; can we act on the student's motivation through his Sense of Self-Efficacy, possibly modifiable by

(C) The Author(s). 2021 Open Access. This article is distributed under the terms of the Creative Commons Attribution 4.0 International License, which permits unrestricted use, distribution, and redistribution in any medium, provided that the original author(s) and source are credited. 
coping strategies? In the socio-cognitive approach, motivation is made up of the following elements: lived experience, vicarious experience, verbal persuasion, emotional and physiological state and, sources of information on the Sense of self- Efficacy. Motivation to study, a dependent variable in this research work, involves the Sense of Self-Efficacy.

\subsection{Sources of Information on the Sense of Perceived Self-Efficacy}

The Sense of Perceived Self-Efficacy (Bandura, 2011) is nourished by personal judgments or by others. It permeates the quality of those judgments. The Sense of Perceived Self-Efficacy also arises from the student's frequent attitudes towards difficult situations: perseverance, patience, rushing forward, procrastination, great anxiety, or anger. The conscious exercise of coping strategies is the independent variable in this investigation. Pedagogical accompaniment via conscious training (Salomon et al., 2006) aims to achieve the planned activity of coping strategy (Skinner \& Zimmer-Gembeck, 2016). Sociocognitive approach, coping strategies are reflected in resourcefulness during difficult learning situations and exams. The student demonstrates coping strategies to deal with blockages and stress and analyzes his problems' nature and sources.

\subsection{The Coping}

In the socio cognitive approach (Bandura, 1989b), coping (Bandura, 1994; Benight et al., 1997; Folkman \& Moskowitz, 2004) means solving problems and dealing with the stress that accompanies problematic situations (Benight et al., 2002). A learner who can do adequate coping controls anxiety due to anticipatory ideas and difficulties in the learning situation. He is forced to resolve the problems arising from this situation and deal with the stress that occurs from it. Coping is, therefore, a process of simultaneous adaptation and regulation of cognition, emotion, and action. Much research has confirmed a causal link between perceived inefficacy (Bandura et al., 1987) and anxiety activation. Besides, coping is also a reliable source of modeling. Bandura (Bandura, 1989b) argues that as agents try, start small, make mistakes, and progress gradually through persevering efforts at coping, these agents fulfill their role as role models. Coping modeling is more convincing because it is visible and accessible to the extent that the subjects compare their skills and the model to conclude their benefit. Observers have the opportunity with a coping model to see the emergence of perseverance efforts in the face of difficulty in the face of failure or the threat of loss before arriving at the desired performance and results. The result is cognitive self-regulation based on a new representation of failure as a consequence of insufficient efforts. Bandura (Bandura, 1986) states that these mental processes promoted by coping modeling are a source of motivation, self-motivation, self-improvement, and practical thinking. Some researchers (Kazdin, 1974; Meichenbaum \& Goodman, 1971) have confirmed the importance of coping modeling over expertise. Kazdin (Kazdin, 1974) tried to prove that coping modeling accompanied by the similarity of personal characteristics between the model and the observers promotes change. Bandura emphasizes the usefulness of teaching coping strategies. In the case of a self-doubting student, these strategies can reassure their ability to learn from the information reported by the model. Coping modeling is likely to be successful when performed by students with a high sense of Self-Efficacy. Bandura (Bandura, 1986) says in this regard that coping modeling, whereby people with limited skills like them achieve progressive mastery through perseverance, can help build a stronger sense of learning efficacy than the modeling of expertise. However, he draws attention to a possible weakness in the notification of the differences between the types of modeling and that to make the modeling factors more tangible, it would be more judicious to focus on how the modeling influences are structured. This mode's function is to help subjects move from dissimilarity to perceived similarity through learning based on observing the model's capacities and strategies. Coping or expert modeling are ways to improve the Sense of Self-Efficacy. Therefore, Bandura 
(Bandura, 1986) proposes to take advantage of the effects of similarity to derive motivational benefits. The transmission of self-regulatory strategies can be done historically through speech describing the ups and downs of a successful experience (example of speech therapy groups). Coping modeling using historically recounted similarity offers agents a better chance of resilient Self-Efficacy in the face of learning and performance difficulties (Bandura 1989c).

\subsection{Pedagogical Support Model}

Inspired by their teaching practice and their research work, Tardif (Tardif 1992), Salomon (Salomon et al., 2006) propose a three-way methodological learning support model. We deemed this support model adequate to link Source of Information of the Sense of Perceived Self-Efficacy (SISPSE) and conscious training to learning strategies. Besides, the model of Salomon et al. 2006 currently offers us a better path towards the operationalization of SISPSE and coping strategies. In the following titles, we describe the components of this model.

\subsection{The Teacher's Observation}

The teacher's observations are the starting point for this process. The teacher is excellent at identifying gaps, difficulties, and off-putting tasks concerning the course objectives. However, these findings do not guarantee the student's development but constitute an initiation to follow by a reaction from the person accompanied. It is a moment of awareness for the learner.

\subsection{Awareness}

A problem exists when the learner realizes it and not only when it leaves the teacher's mouth for the umpteenth time. The effectiveness of a pedagogical intervention thus resides in the guide's attempt to bring out this awareness. In this case, when presenting an exam copy or a written work, a teacher will provoke a better reaction by offering his learners the example of a poorly made copy instead of insisting shortly on a specific idea of this presentation. Those accompanied reactions generally constitute a source of awareness of the competence in question (Salomon et al., 2006). The accompanied student, therefore, marks a retroactive moment before starting his metacognitive activity. Romainville (Romainville, 2007) speaks in this connection of a metacognitive pause. The student becomes aware of the task's objective and the skills acquired and required, the value, and this objective's requirements.

\subsection{Training}

After these first two stages of awareness, awareness, and motivation at work, the teacher proceeds to the training. This last phase respect three moments: a- the scenario: learning takes place about a given subject's context and therefore calls on a determined methodological skill; b- Establish tasks where learning strategies relating to the targeted methodological competence will be applied and practiced; c- self-analysis of these strategies. The student is encouraged to analyze the effectiveness of his approach. At the same time, he will learn to juxtapose them with his learning styles, his usual modes of operation. The model of Salomon et al. (Salomon et al., 2006) emphasizes the metacognitive stage of student awareness. These researchers insist on the importance and the need to involve the student in choosing his strategies to make him responsible for the steps of the whole process. The following figure 1 summarizes this pedagogical support model. 


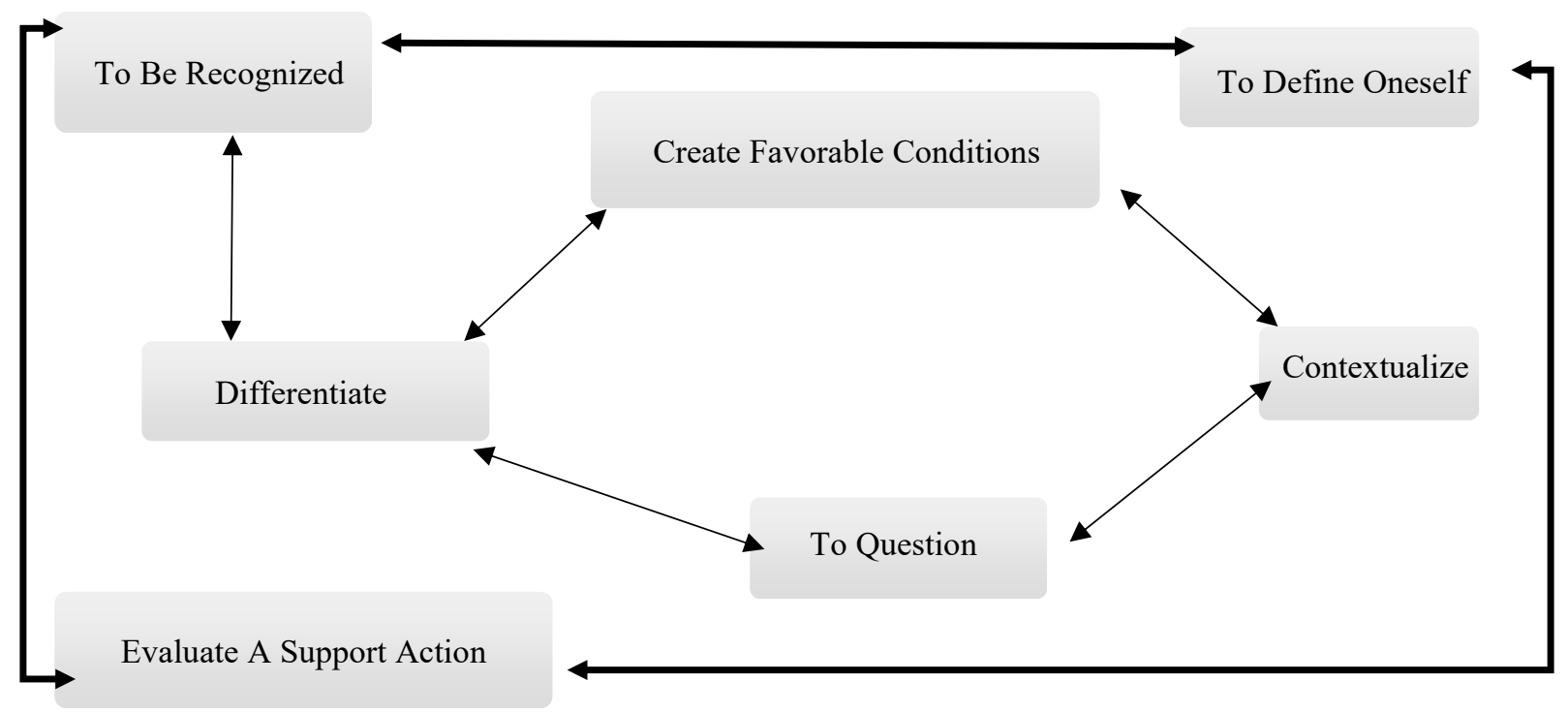

Figure 1. The Salomon et al. 2006 pedagogical support model

Note. Figure 1 summarizes the seven steps to be taken to develop a support action. (Translated from French, Source: The Salomon et al. 2006)

Table 1summarizes the terms of our pedagogical support action. This grid is inspired by an analysis model from the Guidance Service of the University of Liège.

Table1.

The modalities of the pedagogical support action

\begin{tabular}{|c|l|l|}
\hline \multicolumn{2}{|c|}{ Target population } & Students of the first semester of the Law Stream in Arabic \\
\hline \multirow{2}{*}{ Circumstances } & Institution & Faculty of Legal, Economic and Social Sciences University Mohammed V \\
\cline { 2 - 3 } & Period & The first semester of the academic year 2018-2019 \\
\hline Coach & Psychology teacher; communication teacher \\
\hline Object & $\begin{array}{l}\text { Development of methodological skills - university integration - } \\
\text { development of a personal project }\end{array}$ \\
\hline Function & Remediation - Training support \\
\hline Means & Discipline book - Methodological manual - CD-ROM \\
\hline Place & Classroom, educational environment \\
\hline
\end{tabular}

\section{Methodology}

The questionnaire (French and Arabic versions) is used to diagnose the students' motivation and university work methods supposed to modify it. We opted to analyze the SISPSE as an essential component of the motivation to study by using a test of six items after factorial analysis guaranteeing an acceptable threshold of homogeneity (see table 1). In its sociocognitive conception, the SISPSE involves the following dimensions: The experience, the vicarious experience (or modeling), verbal persuasion, the student's emotional or physiological state, Sources of Information on the Sense of Perceived Self-Efficacy (SISPSE). A second test with ten items permeates to analyze Coping strategies as the independent variable. Figure 1 shows the dependent variable and the independent variable, and the training experimentation:

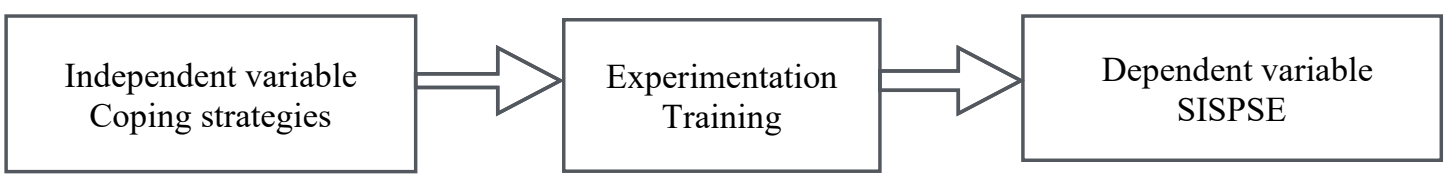

Figure 2. The dependent variable and the independent variable and the experimentation training Note. Figure 2 summarizes the relationship between the master variables involved in this research. Coping strategies should influence SISPSE. 


\section{Items Relating to SISPSE (After Factor Analysis)}

Factor analysis is applied to items' SISPSE, and results of the extraction of the factors are given in table 2:

Table 2 .

Factor analysis applied to items of the SISPSE, and the results of the extraction of the factors

\begin{tabular}{ccccccc}
\hline \multirow{2}{*}{ Components } & \multicolumn{3}{c}{ Initial Eigenvalues } & \multicolumn{3}{c}{ Extraction of sums of squares of selected factors } \\
\cline { 2 - 6 } & Total & \% of Variance & Cumulative \% & Total & \% of Variance & Cumulative \% \\
\hline 1 & 1.993 & 15.332 & 15.332 & 1.993 & 15.332 & 15.332 \\
2 & 1.674 & 12.874 & 28.206 & 1.674 & 12.874 & 28.206 \\
3 & 1.457 & 11.208 & 39.414 & 1.457 & 11.208 & 39.414 \\
4 & 1.321 & 10.161 & 49.576 & 1.321 & 10.161 & 49.576 \\
5 & 1.145 & 8.810 & 58.386 & 1.145 & 8.810 & 58.386 \\
6 & 1.083 & 8.329 & 66.715 & 1.083 & 8.329 & 66.715 \\
\hline
\end{tabular}

Note. Extraction method: Principal component analysis a. six components extracted.

Table 2 indicates that this group's items can summarize most of the information in six subdimensions instead of three as in the theoretical framework. The report represents $66.7 \%$, which is a good percentage. The table of coefficients is given below. Hence, Sources of Information on the SISPSE correspond to these six questions:

- question 1: Overall, feelings of pride; I owe them to my efforts

- question 2: Overall, the feelings of fulfillment I owe them to the encouraging words of the teachers

- question 3: Overall, the feelings of satisfaction I owe them to the encouragement of my parents

- question 4: Overall, the feelings of pride I owe them to the image I have with my peers

- question 5 Overall, when it comes to studying, I judge myself: $\square$ Weak $\square$ Average $\square$ Excellent

- question 6: During the lesson, I do not write anything down since I have the handout

\section{Results}

We correlated with seeing a linear relationship between SISPSE and coping strategies at the pre-test, that is to say, before training experimentation.

Table 3.

The correlation coefficient between the SISPSE and coping strategies in the pre-test

\begin{tabular}{ccc}
\hline & SISPSE (pre-test) & Coping strategies (pre-test) \\
\hline SISPSE (pre-test Pearson correlation & 1.000 & .123 \\
Sig.(unilateral) & 71 & .169 \\
N & .123 & 63 \\
Coping strategies (pre-test) Pearson correlation & .169 & 1.000 \\
Sig. (unilateral) & 63 & 67 \\
N & &
\end{tabular}

We note that the correlation between SISPSE and coping strategies is not significant at pretest. The null hypothesis is maintained (no relationship between these two variables). The linear relationship is statistically improved between these two variables. Thus, we can conclude that the linear relationship between the SISPSE and coping strategies is statistically improved at the pre-test. We also correlated with seeing a linear relationship between SISPSE and post-test coping strategy. 
Table 4.

The correlation coefficient between the SISPSE and coping strategies in the post-test

\begin{tabular}{ccc}
\hline & SISPSE (post-test) & Coping strategies (post-test) \\
\hline SISPSE (post-test) Pearson correlation & 1.000 & -.113 \\
Sig.(unilateral) & 113 & .129 \\
$\mathrm{~N}$ & -0.113 & 103 \\
Coping strategies (post-test) Pearson correlation & .129 & 1.000 \\
Sig(unilateral) & 103 & 113 \\
$\mathrm{~N}$ & &
\end{tabular}

We note that the correlation between the sources of SISPSE and the coping strategies is not significant at the post-test. The null hypothesis is maintained (no relationship between these two variables). The linear relationship is statistically improved between these two variables at the post-test. Thus, we can conclude that the linear relationship between the SISPSE and coping strategies is statistically improved in the post-test.

\section{Results Relating to Coping Strategies}

Table 5.

Items of coping strategies

\begin{tabular}{|c|c|c|}
\hline \multirow{4}{*}{$\begin{array}{l}\text { Coping } \\
\text { strategies }\end{array}$} & $\begin{array}{l}\text { a-Expression of } \\
\text { the Sense of } \\
\text { resourcefulness }\end{array}$ & $\begin{array}{l}\text { Question } 7 . \text { When I am faced with a demanding job, I ask someone for advice } \\
\text { to overcome the difficulty } \\
\text { Question } 8 . \text { Faced with difficult questions, I manage to answer } \\
\text { Question 9. In my studies, I count on the help of teachers }\end{array}$ \\
\hline & $\begin{array}{l}\text { b-Signs of } \\
\text { blockage }\end{array}$ & $\begin{array}{l}\text { Question 10. When faced with difficult questions, I sometimes get stuck } \\
\text { Question 11. Faced with studies, everything is against me, time, teachers, lack } \\
\text { of documents }\end{array}$ \\
\hline & $\begin{array}{l}\text { c-Stress } \\
\text { management }\end{array}$ & $\begin{array}{l}\text { Question } 12 . \text { During the check, I: } \\
\square \text { read the exam questions } \square \text { irritates me a slight } \square \text { shaking and sweating: } \\
\square \text { The pain in my throat and head prevent me from reading the questions } \\
\text { Question } 13 . \text { Before the test, I: } \\
\square \text { sleep, as usual, } \square \text { eat as usual } \\
\square \text { manages to work calmly } \square \text { have lots of coffee and tea } \square \text { I have a headache } \\
\text { Question } 14 \text {. When faced with control situations, I try to stay positive. }\end{array}$ \\
\hline & $\begin{array}{l}\text { d-Difficulty } \\
\text { analysis }\end{array}$ & $\begin{array}{l}\text { Question } 15 . \text { After the tests, I try to: } \\
\square \text { calm down and understand the nature of my difficulties } \square \text { distract and skip } \\
\text { everything } \square \text { I have concerns that carry over to the next exam } \\
\text { Question } 16 \text {. When I am faced with challenging work, I try to analyze the } \\
\text { difficulty and start the work }\end{array}$ \\
\hline
\end{tabular}

Table 6.

The t-student on coping strategies

\begin{tabular}{|l|c|c|c|c|}
\hline & $\begin{array}{c}\text { Average score } \\
\text { (pre-test) }\end{array}$ & $\begin{array}{c}\text { Average score } \\
\text { (post-test) }\end{array}$ & $\mathrm{t}$ & $\mathrm{Sig}$ \\
\hline Experimental group & 19.48 & 20.52 & 1.85 & .003 \\
\hline Control Group 1 & 21.10 & 19.055 & 3.023 & .004 \\
\hline Control Group 1pre-test versus post-test & 21.10 & 19.055 & 2.32 & 0.23 \\
\hline Control Group 2 & - & 19.65 & 1.944 & .053 \\
\hline
\end{tabular}

The mean post-test score of the experimental group (20.52) is higher than that of the pre-test (19.48). This change is significant $(t=-1.858$; significant at .003). We can deduce from this an effect of training in coping strategies (Expression of the Sense of resourcefulness); (Signs of blockage); (Stress management), (Analysis of difficulties) of the student. The mean post-test score of the experimental group (20.52) is higher than that of the control group 1 (post-test: 19.55). This difference is significant $(\mathrm{t}=3.023$; significant at .004). The mean post-test score 
(19.55) is different from that of the pre-test of control group 1 (21.10). This difference is not significant $(t=3.169$; significant at, 72). No change in coping strategies is inferred from this in the students of control group 1. The mean score at the experimental group's post-test (20.52) is different from the mean score (post-test: 19.6500) of the control group 2. This difference is not significant $(\mathrm{t}=1.944$; significant at, 053). We conclude that training in coping strategies (Expression of the Sense of resourcefulness; Signs of blockage; Stress management; Analysis of the difficulties) in the student had substantial effects at the experimental group level.

\section{The Statistics of the Results Relating to the Sources of SISPSE}

The mean post-test score of the experimental group (23.19) is higher than that of the pre-test (19.54). This change is significant $(t=-1.820$, signifying at, 000). We deduce from an effect of training on reflection around the SISPSE. The mean post-test score of the experimental group (23.19) is higher than that of the control group 1 (post-test: 21.093). This difference is not significant $(\mathrm{t}=, 141$; significant at, 008). The mean post-test score of control group 1 is different (21.093) from the pre-test (19.75). This difference is not significant $(t=0.642$, sig at $0.537)$. The mean score at the experimental group's post-test (23.17) is different from the mean score (post-test: 22.78$)$ of the control group 2. This difference is not significant $(\mathrm{t}=.850$; means to, 398). Training to modify SISPSE the sources of intra and extra personal information contributing or developing or not the Sense of Personal Effectiveness) in the student had the expected effects at the level of the experimental group (see Table 7).

Table 7

The t-student on the sources of SISPSE

\begin{tabular}{|l|c|c|c|c|}
\hline & $\begin{array}{c}\text { Average score } \\
\text { (pre-test) }\end{array}$ & $\begin{array}{c}\text { Average score } \\
\text { (post-test) }\end{array}$ & $\mathrm{t}$ & Sig \\
\hline Experimental group & 19.54 & 23.19 & 14.53 & .000 \\
\hline Control group 1 & 19.75 & 21.093 & .141 & .008 \\
\hline Control group 1 pre-test versus post-test & 17.75 & 21.093 & 0.642 & 0.537 \\
\hline Control group 2 & - & 22.78 & .850 & .398 \\
\hline
\end{tabular}

\section{Discussion}

The SISPSE has sources that are sometimes intrinsic and sometimes extrinsic to the person. Thus, a student's motivation would be better off when his sources are innate rather than extrinsic. The methodological support was intended, among other things, to train students to question all the "labels" that had stuck to them since primary school and to learn to self-assess by setting goals and checking whether or not they have achieved them. The objective's activities planned for a purpose (tabula rasa, the outlet, the project or the coat of arms, the family tree, the prerequisites) is twofold: to work on Sources of information on the Sense of Self-Efficacy and the quality of the judgments towards oneself, with the prospect of evolving towards selfevaluation and performance. Coping strategies are reflected in the following indicators: expression of a sense of resourcefulness, management of blockage signs, metacognitive analysis of learning difficulties, and stress management. The methodological support program's activities require the students' involvement and a sense of resourcefulness that is not common among students in this field.

On the one hand, they were encouraged to speak in public by showing management of the stage fright, shyness, and blockade they often suffered. The activities that enabled us to train are interviewing the students with a legal professional on their student life. These achievements have helped them in the professional environment, the oral presentation on the results of this interview. Methodological training in the practice of these strategies had positive effects at the experimental group level. The results of this research also show the aspects on which we have stumbled. We cite a few here: 
- Analysis of all the constituents of the Sense of Personal Efficiency, the main component of motivation. We think it would be more profitable and more manageable to restrict to a few of these constituents. Consideration must be given to the resources used for the research and for the action to take.

- The duration of the educational sequence: it seems necessary to limit the objectives to the time allotted to this sequence. Besides, the six-month period seems insufficient to us, in particular, to repeat the exercises.

- The experience carried out on the representative sample of this population (the students of the first-year semester first legal sciences taught in Arabic at the Faculty of Legal, Economic, and Social Sciences of Mohammed V Souissi University) is a vague generalization of the results obtained. Hence the plan to take up the experience with other groups and different sectors.

Finally, we quote Rogers, who states that education is a total operation that addresses the whole personality and not transmitting knowledge. Bandura believes that motivation is what one believes to be able to do. The results mean that the methodological support makes it possible to train students in coping strategies. We succeed in confirming the second hypothesis and answering the second question by subsuming that the support makes it possible to modify the motivation for studies and attenuate the difficulties encountered by developing the feeling of SISPSE and its constituents.

\section{Conclusion}

This research's objective was to motivate (mainly SISPSE) to study and facilitate their entry into higher education. The socio-cognitive definition of motivation was of great importance because it offers the possibility of declining motivation for learning in dimensions (including SISPSE). This research's main objective was to motivate them to study and facilitate their entry into higher education. The literature review (theories and experience) decided to opt for the socio-cognitive definition given its enabled in many areas, including learning. Our interest focused on the following main research question: Can we act on motivation to study?

The choice of the socio-cognitive definition of the concept of motivation was of great importance for our experiment's unfolding. This definition offers the possibility of breaking down learning motivation into dimensions and sub-dimensions and generally observable and measurable indices. Methodological support constitutes an adequate response in more than one way:

- methodological training responded to SISPSE put into context. Motivating legal science students corresponds to activities and training in university work methods. Therefore, the student can cope with learning difficulties by developing coping strategies contributing to the improvement of SISPSE (the main factor in the concept of motivation).

- The methodological support model chosen (Tardif 1992, Salomon et al. 2006) is triply focused: 1- the teacher's observation and observations constitute a starting point for the process and give it some legitimacy.

- awareness is the second equally important condition for the legitimacy of the support. This awareness (or retroactive moment, or metacognitive break (Romainville, 2007) allows the supportive action established and prepares for training.

- training is putting into practice the first two stages based on a scenario, the choice of tasks and activities, and the self-analysis of his (student) strategies.

The socio-cognitive approach and the methodological support are directed simultaneously towards autonomy in learning, the semantic contribution of the principle of reciprocal selfdeterminism, and the importance of context in analyzing and understanding the concept of motivation. 
We can only claim to generalize our research results after replicating this experience with a larger population of other levels of the same stream, other streams, and other faculties. On the other hand, these results mean obtaining an improvement in the Sense of Personal Effectiveness, an essential component of human motivation, methodological, metacognitive, managerial, self-regulatory training, and all the experimental group methods. The means of the pre-test and post-test of the experimental group generally changed. We conclude that:

- It is possible to act and reduce learning difficulties for student lawyers by changing their motivation,

- Methodological support and psycho-educational support improve the Sense of Personal Effectiveness and the learning strategies they convey.

- Methodological support was an adequate response in more than one way:

- the methodological training responded to the operationalization of SISPSE in context. Motivating legal science students corresponds to activities and training in university work methods. Therefore, the student can cope with learning difficulties by developing coping strategies contributing to improving the Sense of Personal Effectiveness (the main factor in the concept of motivation). -The methodological support model chosen (Tardif,1992, Salomon et al. 2006) is threefold: 1- the teacher's observation and observations constitute a starting point for the process and give it some legitimacy. Following the results obtained, we believe that the dependent variables (the sources of information on the feeling of personal effectiveness) and independent (the coping strategies) were able to take advantage of the theoretical and methodological framework chosen. The socio-cognitive approach and methodological support are directed simultaneously towards autonomy in learning, the semantic contribution of the principle of reciprocal self-determinism, and the importance of context in the analysis and understanding of the concept of motivation. We can only claim to generalize our research results after replicating this experience with a larger population of other levels of the same stream, other streams, and other faculties. We conclude that:

- It is possible to act and reduce learning difficulties for student lawyers by changing their motivation,

- Methodological support and psycho-educational support improve the Sense of Personal Effectiveness and the learning strategies they convey.

\section{References}

Bandura, A. (1986). Social foundations of thought and action: A social cognitive theory. Eng. Leewood Cliffs, NJ: Prentice-Hall.

Bandura A, Cioffi D, Taylor CB, Brouillard ME. (1987). Perceived self-efficacy in coping with cognitive stressors and opioid activation. J Pers Soc Psychol. 1988 Sep; 55(3):479-88. DOI: 10.1037//0022-3514.55.3.479. PMID: 3171918.

Bandura, A. (1989a). Social cognitive theory. In R. Vasta (Ed.), Annals of child development. Vol. 6. Six theories of child development (pp. 1-60). Greenwich, CT: JAI Press.

Bandura, A.(1989b). Human agency in social cognitive theory. American Psychologist, Vol 44, No.9, 1175-1184

Bandura, A. (1989c). Regulation of cognitive processes through perceived self-efficacy. Developmental Psychology, 25(5), 729-735. https://doi.org/10.1037/0012-1649.25.5.729

Bandura, A. (1993). Perceived self-efficacy in cognitive development and functioning. Educational Psychologist, 28(2). 117-148

Bandura A. (1994) Social Cognitive Theory and Exercise of Control over HIV Infection. In: DiClemente R.J., Peterson J.L. (eds) Preventing AIDS. AIDS Prevention and Mental Health. 
Bandura, A. (2011). On the Functional Properties of Perceived Self-Efficacy Revisited. Journal of Management, 38(1), 9-44. doi:10.1177/0149206311410606

Benight, C. C., Antoni, M. H., Kilbourn, K., \& Ironson, G. (1997). Coping self-efficacy buffers psychological and physiological disturbances in HIV- infected men following a natural disaster. Health Psychology, 16, 248-255.Folkman S., \& Moskowitz, J. T. (2004). Coping: Pitfalls and promises. Annual Review of Psychology, 55, 745-774.

Benight, C.C., \& Harper, M.L. (2002). Coping self-efficacy perceptions as a mediator between acute stress response and long-term distress following natural disasters. Journal of Traumatic Stress, 15, 177-186.

Deci, E., \& Ryan, R. (2000). The "What" and "Why" of Goal Pursuits: Human Needs and the Self-Determination of Behavior. Psychological Inquiry, 11(4), 227-268. Retrieved April 14, 2021, from http://www.jstor.org/stable/1449618

Earley, P. (1994). Self or Group? Cultural Effects of Training on Self-Efficacy and Performance. Administrative Science Quarterly, 39(1), 89-117. doi:10.2307/2393495

Salmon, D., Cobut, B., Coupremanne, M., Delhaxhe, M., Dubois, P., Goemaere, S., Houart, M., Noël, B., Pollet, M.C. \& Slosse, P. (2006). L'accompagnement pédagogique des étudiants dans l'enseignement supérieur : conditions, actions et questions sur les critères de qualité. Actes du XXIIIe Congrès de l'Association Internationale de Pédagogie Universitaire. Monastir : Faculté de Pharmacie de l'Université de Monastir.

Hsu, M.-H., Ju, T. L., Yen, C.-H., \& Chang, C.-M. (2007). Knowledge sharing behavior in virtual communities: The relationship between trust, self-efficacy, and outcome expectations. International Journal of Human-Computer Studies, 65 (2), 153-169. doi: 10.1016/j.ijhcs.2006.09.003

Kazdin, A. E. (1974). Covert modeling, model similarity, and reduction of avoidance behavior. Behavior Therapy, 5(3), 325-340. doi:10.1016/s0005-7894(74)80002-x

Meichenbaum, D. H., \& Goodman, J. (1971). Training impulsive children to talk to themselves: A means of developing self-control. Journal of Abnormal Psychology, 77(2), 115-126. https://doi.org/10.1037/h0030773

Rogers, C. R. (1983). Freedom to Learn for the 80s. Columbus, OH: Charles E. Merrill Publishing Company

Romainville, M. (2007). Conscience, métacognition, apprentissage : le cas des compétences méthodologiques. In : La conscience chez l'enfant et chez l'élèveFrancisco Pons et Pierre André Doudin (Eds), Québec : Presses de l'Université de Québec

Skinner, E. A., \& Zimmer-Gembeck, M. (2016). Coping. Encyclopedia of Mental Health, 350357. doi:10.1016/b978-0-12-397045-9.00036-7

Springer, Boston, MA. https://doi.org/10.1007/978-1-4899-1193-3_3Schunk, H.D \&

Stajkovic, A.D. \& Luthans, F. (1998). Social cognitive theory and self-efficacy: going beyond traditional motivational and behavioral approaches. Organizational Dynamics, Vol.26, No 4

Tardif J. (1992). Pour un enseignement stratégique ; l'apport de la psychologie cognitive. Montréal, Logiques Ed.

Tolli, A. P., \& Schmidt, A. M. (2008). The role of feedback, causal attributions, and selfefficacy in goal revision. Journal of Applied Psychology, 93(3), 692-701. https://doi.org/10.1037/0021-9010.93.3.692 
Wernersbach, B.M; Crowley, S.L; Bates, S.C, and Rosenthal, C. (2014). Study Skills Course Impact on Academic Self-Efficacy. Journal of Developmental Education, Vol 37, Issue 3

Zimmerman, B.J. (1995a). Self-efficacy and educational development. In Self-efficacy in changing societies, A, Bandura (ed). Cambridge University Press

Zimmerman, B.J. (1995b). Self-regulation involves more than metacognition: A social cognitive perspective, Educational Psychologist, 30:4, 217-221, DOI: $10.1207 / \mathrm{s} 15326985 \mathrm{ep} 3004 \_8$

Zimmerman, B.J.Eds. (2008). Motivation and self-regulated learning. Theory, Research, and Applications. Lawrence Erlbaum Association. 


\section{Appendices}

\section{Training schedule (extract)}

\section{Exercise 1: Tabula rasa}

Objective: To allow the student to express himself about his choices or his obligations, his arrival at this faculty, to talk about painful or motivating things, to wonder about the existence of a personal project

Keywords: Icebreaker, presentations, shyness, psychological comfort, positive or negative emotional ties, group, teacher, free expression

Duration: $30 \mathrm{~min}$

Instructions: Go to the board, introduce yourself, say what you want, keep what you don't want to communicate; answer the group's questions if you can answer the professor's questions: is studying law a choice or a coincidence? Do you have a dream? A project? end of this activity, draw optimistic conclusions: the crucial opportunities in the sector, the privilege of being at university, the chance to have passed the baccalaureate, and the need to plan

\section{Exercise 2: The outlet}

Objective: Identify the sources of suffering and self-denigration in the student about learning generally and learning French in particular

Keywords: Surroundings, school, "mistress," responsibility, age, pain, the best of oneself, belief in one's qualities, free speech

Material: Ragdoll or inflatable representing a teacher

Duration: $30 \mathrm{~min}$

Instructions: This is one of your former teachers. What do you have to say to him?

\section{Exercise 3: Personal project: the coat of arms}

Objective: To encourage the student to think about his person, his choices, his qualities, and finally, his project

Keywords: self, others, studies, future, work

Material: Board, markers

Support: Indicative sheet listed in the table

Duration: 30 min

Instructions: Express yourself on:

\begin{tabular}{|l|l|}
\hline One of your qualities & One of your faults \\
\hline A role model & A person you underestimate \\
\hline A dream & A nightmare \\
\hline A job you like & A job you don't prefer to do \\
\hline \multicolumn{2}{|c|}{ A project } \\
\hline
\end{tabular}

\section{Exercise 4: Life course}

Objective: Work on student motivation

Keywords: personal elements, socio-professional elements

Material: Large format paper + markers, adhesive tape

Support: Story, discussion

Duration: $45 \mathrm{mn}$

Instructions: Draw a straight line on your form (use the projected model)

Day of your birth Today

Facts, milestones, significant dates 
- From the date of your birth, present on this line, the events appear to you to be the most significant

- Comment

\section{Exercise 5: The genealogical tree}

Objective: To encourage students to meditate on the sources of their motivation and demotivation

Keywords: Family, socio-cultural determinants, self, others, construction of meaning, personal project, family project, education, ignorance, outstanding people

Material: Large format papers + Markers

Support: The story, a model of a family tree

Duration: 45 mins

Instructions: Observe the projected family tree model

Produce your tree based on the proposed model

Comment

The family tree (model):

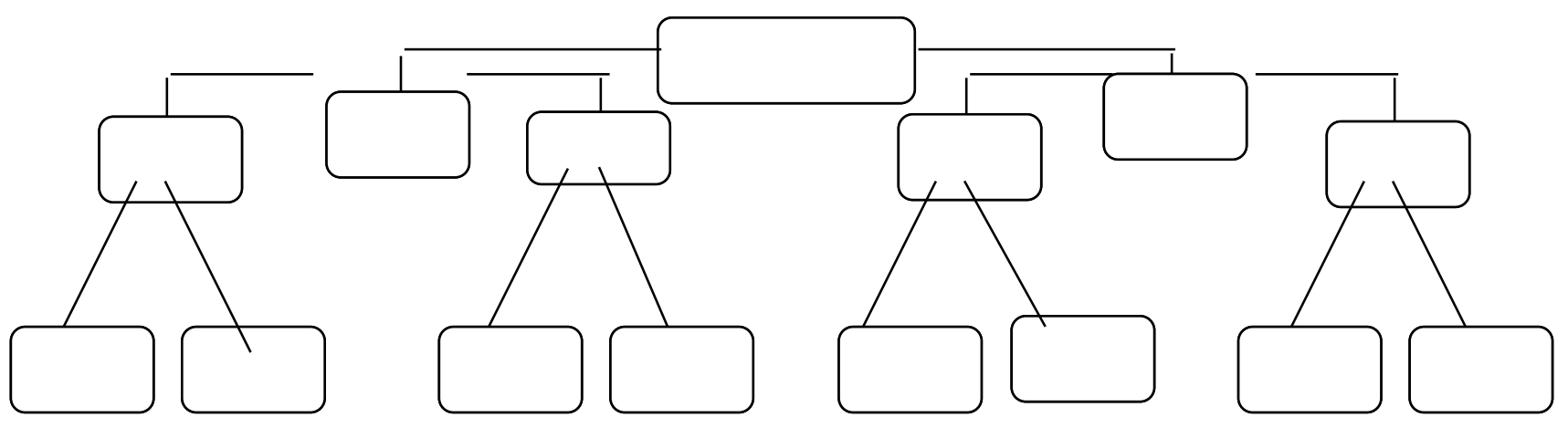

